\title{
Generalized Cesàro Summable Difference Sequence Spaces
}

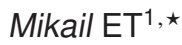 \\ ${ }^{1}$ Department of Mathematics, Fırat University, 23119 Elazığ, Turkey
}

\begin{abstract}
Et (M. Et, On some generalized Cesàro difference sequence spaces, İstanbul Üniv. Fen Fak. Mat. Derg. 55/56 (1996/97), 221-229) introduced Cesàro difference sequence spaces $C_{p}\left(\Delta^{m}\right)(1 \leq p<\infty), C_{\infty}\left(\Delta^{m}\right)$ and studied some topological properties. In this paper we continue to examine others relations with related the sequence spaces $C_{1}\left(\Delta^{m}\right)$ and $C_{\infty}\left(\Delta^{m}\right)$.
\end{abstract}

\section{Introduction}

Let $w$ be the set of all sequences of real or complex numbers and $\ell_{\infty}, c$ and $c_{0}$ be respectively the Banach spaces of bounded, convergent and null sequences $x=\left(x_{k}\right)$ with the usual norm $\|x\|_{\infty}=\sup \left|x_{k}\right|$, where $k \in \mathbb{N}=\{1,2, \ldots\}$, the set of positive integers. Also by $b s, c s, \ell_{1}$ and $\ell_{p}$; we denote the spaces of all bounded, convergent, absolutely summable and $p$-absolutely summable series, respectively.

A sequence space $X$ with a linear topology is called a $K$-space provided each of the maps $p_{i}$ : $X \rightarrow \mathbb{C}$ defined by $p_{i}(x)=x_{i}$ is continuous for each $i \in \mathbb{N}$, where $\mathbb{C}$ denotes the complex field. A $K$-space $X$ is called an $F K$-space provided $X$ is a complete linear metric space. An $F K$-space whose topology is normable is called a $B K$-space. We say that an $F K$-space $X$ has $A K$ (or has the $A K$ property), if $\left(e_{k}\right)$ ( the sequence of unit vectors) is a Schauder bases for $X$.

Study of difference sequence spaces is a recent development in the summability theory. The approach of using differences of terms does not help for all the problems involving sequences. However, for many sequences, the use of differences can be very profitable and, moreover, the differences themselves prove extremely valuable in many other contexts. Sometimes a situation may arise that we have a sequence at hand and we are interested in sequences formed by its successive differences and in the structure of these new sequences.

The notion of difference sequence spaces was introduced by Kızmaz [16] and the notion was generalized by Et and Çolak [11]. Later on Et and Nuray [12] generalized these sequence spaces to the following sequence spaces. Let $X$ be any sequence space and let $m$ be a non-negative integer. Then,

$$
\Delta^{m}(X)=\left\{x=\left(x_{k}\right):\left(\Delta^{m} x_{k}\right) \in X\right\}
$$

$\Delta^{0} x=\left(x_{k}\right), \Delta^{m} x=\left(\Delta^{m-1} x_{k}-\Delta^{m-1} x_{k+1}\right)$ and so $\Delta^{m} x_{k}=\sum_{i=0}^{m}(-1)^{i}\left(\begin{array}{c}m \\ i\end{array}\right) x_{k+i}$. The sequence spaces $\Delta^{m}(X)$ are Banach spaces normed by

^e-mail: mikailet68@gmail.com 


$$
\|x\|_{\Delta}=\sum_{i=1}^{m}\left|x_{i}\right|+\left\|\Delta^{m} x_{k}\right\|_{\infty} .
$$

Let $X$ be any sequence space, if $x \in X\left(\Delta^{m}\right)$ then there exists one and only one $y=\left(y_{k}\right) \in X$ such that

$$
\begin{aligned}
x_{k} & =\sum_{i=1}^{k-m}(-1)^{m}\left(\begin{array}{c}
k-i-1 \\
m-1
\end{array}\right) y_{i}=\sum_{i=1}^{k}(-1)^{m}\left(\begin{array}{c}
k+m-i-1 \\
m-1
\end{array}\right) y_{i-m}, \\
y_{1-m} & =y_{2-m}=\cdots=y_{0}=0
\end{aligned}
$$

for sufficiently large $k$, for instance $k>2 m$. Recently, a large amount of work has been carried out by many mathematicians regarding various generalizations of difference sequence spaces. For a detailed account of difference sequence spaces one may refer to ([1-12],[14-15]).

The Cesàro sequence spaces $C e s_{p}$ and $C e s_{\infty}$ have been introduced by Shiue [19]. Jagers [13] has determined the Köthe duals of the sequence space $\operatorname{Ces}_{p}(1<p<\infty)$. It can be shown that the inclusion $\ell_{p} \subset \operatorname{Ces}_{p}$ is strict for $1<p<\infty$. Later on the Cesàro sequence spaces $X_{p}$ and $X_{\infty}$ of non-absolute type are defined by $\mathrm{Ng}$ and Lee ([17],[18]).

\section{Topological Properties of $C_{1}\left(\Delta^{m}\right)$ and $C_{\infty}\left(\Delta^{m}\right)$}

In this section we prove some results involving the sequence spaces $C_{1}\left(\Delta^{m}\right)$ and $C_{\infty}\left(\Delta^{m}\right)$.

Definition 1 Let $m$ be a non-negative integer. We define the following sequence spaces:

$$
\begin{aligned}
& C_{1}\left(\Delta^{m}\right)=\left\{x=\left(x_{k}\right): \lim _{n} \frac{1}{n} \sum_{k=1}^{n}\left(\Delta^{m} x_{k}-L\right)=0\right\}, \\
& C_{\infty}\left(\Delta^{m}\right)=\left\{x=\left(x_{k}\right): \sup _{n}\left(\frac{1}{n} \sum_{k=1}^{n} \Delta^{m} x_{k}\right)<\infty\right\} .
\end{aligned}
$$

The above sequence spaces contain some unbounded sequences for $m \geq 1$, for example let $x=$ $\left(k^{m}\right)$, then $x \in C_{\infty}\left(\Delta^{m}\right)$, but $x \notin \ell_{\infty}$.

Theorem 2 The sequence spaces $C_{1}\left(\Delta^{m}\right)$ and $C_{\infty}\left(\Delta^{m}\right)$ are Banach spaces normed by

$$
\|x\|_{\Delta}=\sum_{i=1}^{m}\left|x_{i}\right|+\sup _{n} \frac{1}{n}\left|\sum_{k=1}^{n} \Delta^{m} x_{k}\right| .
$$

Proof. Prof follows from Theorem 2.2 of Et and Nuray [12].

Theorem $3 \ell_{\infty}\left(\Delta^{m-1}\right) \subset C_{1}\left(\Delta^{m}\right)$ and the inclusion is strict. 
Proof. Let $x \in \ell_{\infty}\left(\Delta^{m-1}\right)$, then there exists $M>0$ such that $\left|\Delta^{m-1} x_{k}\right| \leq M$, for all $k \in \mathbb{N}$. On the other hand, we can write

$$
\begin{aligned}
\left|\frac{1}{n} \sum_{k=1}^{n} \Delta^{m} x_{k}\right| & =\frac{1}{n}\left|\left(\Delta^{m} x_{1}+\Delta^{m} x_{2}+\ldots+\Delta^{m} x_{n}\right)\right| \\
& =\frac{1}{n}\left|\left\{\left(\Delta^{m-1} x_{1}-\Delta^{m-1} x_{2}\right)+\left(\Delta^{m-1} x_{2}-\Delta^{m-1} x_{3}\right)+\ldots+\left(\Delta^{m-1} x_{n}-\Delta^{m-1} x_{n+1}\right)\right\}\right| \\
& =\frac{1}{n}\left|\left\{\Delta^{m-1} x_{1}-\Delta^{m-1} x_{n+1}\right\}\right| \\
& \leq \frac{1}{n}\left|\Delta^{m-1} x_{1}\right|+\frac{1}{n}\left|\Delta^{m-1} x_{n+1}\right| \\
& \leq \frac{2 M}{n} \rightarrow 0,(n \rightarrow \infty) .
\end{aligned}
$$

So $x \in C_{1}\left(\Delta^{m}\right)$. For strict inclusion, observe that $\left(k^{m}\right) \in C_{1}\left(\Delta^{m}\right)$ but $\left(k^{m}\right) \notin \ell_{\infty}\left(\Delta^{m-1}\right)$ ( If $x_{k}=k^{m}$, then $\Delta^{m} x_{k}=(-1)^{m} m !$ and $\Delta^{m-1} x_{k}=(-1)^{m+1} m !\left[k+\frac{m-1}{2}\right]$ for all $\left.k \in \mathbb{N}\right)$.

Theorem 4 The sequence spaces $C_{1}\left(\Delta^{m-1}\right)$ and $c\left(\Delta^{m}\right)$ overlap without containing each other, but $c\left(\Delta^{m}\right) \subset C_{1}\left(\Delta^{m}\right)$ and the inclusion is strict.

Proof. Proof is similar to that of Theorem 3.

The proof of the following result is easy, so we state without proof.

Theorem $5 C_{1}\left(\Delta^{m}\right)$ is a closed subspace of $C_{\infty}\left(\Delta^{m}\right)$.

Theorem $6 C_{1}\left(\Delta^{m}\right)$ is a nowhere dense subset of $C_{\infty}\left(\Delta^{m}\right)$.

Proof. Proof follows from the fact that $C_{1}\left(\Delta^{m}\right)$ is a proper and complete subspace of $C_{\infty}\left(\Delta^{m}\right)$.

Theorem $7 C_{\infty}\left(\Delta^{m}\right)$ is not separable, in general.

Proof. Proof follows from Theorem 5 of Bhardwaj et al. [5].

Theorem $8 C_{\infty}\left(\Delta^{m}\right)$ does not have Schauder basis.

Proof. Proof follows from the fact that if a normed space has a Schauder basis, then it is separable.

Theorem $9 C_{1}\left(\Delta^{m}\right)$ is separable. 
Proof. Proof follows from Theorem 2.5 of Et and Nuray [12].

Theorem $10 C_{1}\left(\Delta^{m}\right)$ does not have the AK property.

Proof. Let $x=\left(x_{k}\right)=\left(k^{m}\right)=\left(1^{m}, 2^{m}, 3^{m}, 4^{m}, \ldots\right) \in C_{1}\left(\Delta^{m}\right)$. Consider the $n^{\text {th }}$ section of the sequence $\left(x_{k}\right)$ as $x^{[n]}=\left(1^{m}, 2^{m}, 3^{m}, 4^{m}, \ldots n^{m}, 0,0, \ldots\right)$. Then

$$
\begin{aligned}
\left\|x-x^{[n]}\right\|_{\Delta} & =\left\|\left(0,0,0,0, \ldots 0, n^{m+1}, n^{m+2}, \ldots\right)\right\|_{\Delta} \\
& =\frac{1}{n}\left[(-1)^{m+1} m !\left((n+1)+\frac{m-1}{2}\right)\right]
\end{aligned}
$$

which does not tend to 0 as $n \rightarrow \infty$.

\section{References}

[1] B. Altay and F. Basar, On the fine spectrum of the difference operator $\Delta$ on $c_{0}$ and $c$, Inform. Sci. 168(1-4) (2004), 217-224.

[2] Y. Altin, Properties of some sets of sequences defined by a modulus function, Acta Math. Sci. Ser. B Engl. Ed. 29(2) (2009), 427-434.

[3] Y. Altin ; M. Et and R. Çolak, Lacunary statistical and lacunary strongly convergence of generalized difference sequences of fuzzy numbers, Comput, Math. Appl. 52(6-7) (2006), 1011-1020.

[4] V. K. Bhardwaj and S. Gupta, Cesàro summable difference sequence space, J. Inequal. Appl. 2013:315 (2013), 9 pp.

[5] V. K. Bhardwaj ; S. Gupta and R. Karan, Köthe-Toeplitz duals and matrix transformations of Cesàro difference sequence spaces of second order, J. Math. Anal. 5(2) (2014), 1-11.

[6] M. Et, On some generalized Cesàro difference sequence spaces, İstanbul Üniv. Fen Fak. Mat. Derg. 55/56 (1996/97), 221-229.

[7] M. Et ; H. Altinok and Y. Altin, On some generalized sequence spaces, Appl. Math. Comput. 154(1) (2004), 167-173.

[8] M. Et, Generalized Cesàro difference sequence spaces of non-absolute type involving lacunary sequences, Appl. Math. Comput. 219(17) (2013), 9372-9376.

[9] M. Et ; M. Mursaleen and M. Iş1k, On a class of fuzzy sets defined by Orlicz functions, Filomat 27(5) (2013), 789-796.

[10] M. Et and M. Işı1k, On $\alpha$-dual spaces of generalized difference sequence spaces, Appl. Math. Lett. 25(10) (2012), 1486-1489.

[11] M. Et and R. Colak, On generalized difference sequence spaces, Soochow J. Math. 21(4) (1995), 377-386.

[12] M. Et and F. Nuray, $\Delta^{m}-$ statistical convergence, Indian J. Pure Appl. Math. 32(6) (2001), 961969.

[13] A. A. Jagers, A note on Cesàro sequence spaces, Nieuw Arch. Wisk. 22(3) (1974), 113-124.

[14] M. Işik, On statistical convergence of generalized difference sequences, Soochow J. Math. 30(2) (2004), 197-205.

[15] M. Mursaleen ; R. Çolak and M. Et, Some geometric inequalities in a new Banach sequence space, J. Inequal. Appl. (2007), Art. ID 86757, 6 pp.

[16] H. Kızmaz, On certain sequence spaces, Canad. Math. Bull. 24(2) (1981), 169-176. 
[17] P. N. Ng and P. Y. Lee, Cesàro sequence spaces of non-absolute type, Comment Math. 20 (1978), 429-433.

[18] P. N. Ng and P. Y. Lee, On the associate spaces of Cesàro sequence space, Nanta Math. 9(2) (1976), 168-170.

[19] J. S. Shiue, On the Cesàro sequence space, Tamkang J. Math. 1(1) (1970), 19-25. 